\title{
The Contribution of Anthroposophic Medicine to Self-Management: An Exploration of Concepts, Evidence, and Patient Perspectives
}

\author{
Erik W. Baars ${ }^{a-c}$ Evi B. Koster ${ }^{a}$ John Verhoef ${ }^{a}$ \\ a University of Applied Sciences Leiden, Leiden, The Netherlands; \\ ${ }^{b}$ Louis Bolk Institute, Driebergen, The Netherlands; \\ ${ }^{\mathrm{c}}$ ESCAMP - European Scientific Cooperative on Anthroposophic Medicinal Products, Freiburg, Germany
}

\section{Keywords}

Anthroposophic medicine - Self-management .

Patient experiences - Patient perspectives

\section{Summary}

Background: In Western healthcare policies, promotion of self-management of patients is an important topic. Currently, there is also a worldwide interest in the integration of complementary and alternative medicine (CAM) and conventional medicine into integrative medicine. This article explores the contribution of anthroposophic medicine (AM) to the promotion of self-management of patients. Material and Methods: The scientific literature on concepts of, evidence on and experiences of patients with AM was explored. Results: The AM approach contributes to: (1) a patient-centered, collaborative promotion of patient self-management by means of application of basic values (equivalence, servitude, and presence of mind) and specific methods; (2) a better coping with health-related issues by providing a spiritual worldview that serves as a coping strategy; by treating patients in such a way that they (further) develop selfregulating functioning, both on the physiological and the psychosocial level, thus enabling the self-management of disease-related symptoms; and by treating with (nonverbal) therapies that improve emotion-focused coping skills; and (3) a better self-monitoring of: one's own activity during treatment and in dealing with treatmentand health-related issues, and the physiological and/or psychological responses to these (self-reflection) activities. Conclusion: AM provides specific contributions to promoting self-management of patients.

(C) 2017 S. Karger GmbH, Freiburg

\author{
Schlüsselwörter \\ Anthroposophische Medizin - Selbstmanagement . \\ Patientenerfahrungen · Patientenperspektiven
}

\section{Zusammenfassung}

Hintergrund: In der Gesundheitspolitik der westlichen Welt ist die Förderung des Selbstmanagement von Patienten ein wichtiges Thema. Derzeit gibt es auch ein weltweites Interesse an der Integration von Komplementär- und Alternativmedizin (CAM) sowie konventioneller Medizin in die Integrative Medizin. Dieser Artikel untersucht den Beitrag der anthroposophischen Medizin (AM) zur Förderung des Selbstmanagement von Patienten. Material und Methoden: Die wissenschaftliche Literatur über AM (Konzepte, empirische Belege zu Patientenerfahrungen) wurde untersucht. Ergebnisse: Der AMAnsatz trägt bei zu 1) einer patientenorientierten, kollaborativen Förderung des Selbstmanagement durch die Anwendung von Grundwerten (Gleichberechtigung, Dienstbereitschaft und Geistespräsenz) und spezifischen Methoden; 2) einer besseren Bewältigung gesundheitsbezogener Probleme durch das Vorhandensein einer spirituellen Weltanschauung, die als Bewältigungsstrategie dient, durch Förderung der Selbstregulation auf der physiologischen und der psychosozialen Ebene, was das Selbstmanagement von Krankheitsbeschwerden ermöglicht, und durch non-verbale Therapieverfahren, die emotionsfokussierte Bewältigungsfähigkeiten verbessern können; 3) einer besseren Selbstbeobachtung, sowohl der eigenen Tätigkeiten während der Therapie als auch des Umgangs mit Fragen zur Therapie und zur Gesundheit sowie der physiologischen und/oder psychologischen Reaktionen auf diese (selbstreflexiven) Tätigkeiten. Schlussfolgerung: AM bietet spezifische Beiträge zur Förderung des Patientenselbstmanagement.

\section{KARGER

(c) 2017 S. Karger GmbH, Freiburg 


\section{Introduction}

In many Western countries, an important topic in healthcare policies is the promotion of self-management of patients (with chronic diseases). Self-management is often broadly defined as (1) the individual's ability to properly cope with symptoms, treatment, physical and social consequences of the chronic disorder, and the associated adjustments in life style, and (2) the ability to cognitively self-monitor one's own health status and to subsequently exhibit behavioral and emotional responses that contribute to a satisfying quality of life [1]. Self-management promotion involves a patientcentered, collaborative approach to care and enhances patients' self-management (skills) by promoting activation, self-efficacy, education, and empowerment of patients to seek solutions and to have control over their own lives [2,3].

Currently, there is also a worldwide interest in the integration of different types of complementary and alternative medicine (CAM), on the one hand, and conventional medicine, on the other hand, into integrative medicine (IM). For example, in the USA, the Consortium of Academic Health Centers for Integrative Medicine, nowadays called the Academic Consortium for Integrative Medicine \& Health (The Consortium), was established in 2000. Since then, the number of universities being a member of this consortium has increased from 11 to 63 in North America. This demonstrates an increasing interest in CAM based on different traditional medical systems in the academic world [4]. In 2014, the World Health Organization (WHO) developed and launched the 'WHO Traditional Medicine Strategy 2014-2023'. The strategy demonstrates that all over the world CAM is used and should be integrated with conventional medicine into IM [5].

IM is based on 4 pillars: (1) a horizontal relationship between the doctor/therapist (coach) and the patient (co-producer); (2) an active role of the patient in prevention (lifestyle), well-being, and therapy and healing processes; (3) the use of evidence-based, safe, and effective conventional and complementary therapies; and (4) the use of healing environments [4]. One type of IM is anthroposophic medicine (AM), which was founded in the early 1920's [6]. The fundament of AM was provided by the philosopher Rudolf Steiner and the physician Ita Wegman [7]. They cooperated to integrate the knowledge from conventional medicine and science and the knowledge from spiritual science (anthroposophy) into the concept and practice of AM. Starting in Central Europe, AM is currently practiced and taught throughout most European countries and in more than 80 countries worldwide. In 2012, the figures for Europe were as follows: AM was practiced by more than 2,700 fully AM-trained licensed medical doctors in 22 European Union (EU) member states, Norway, and Switzerland. In addition, AM was prescribed by about 15,000 physicians with various levels of training (estimate, based on various data). AM was provided in 24 hospitals in $5 \mathrm{EU}$ member states and Switzerland (14 of those had accident and emergency services, 2 of those were university teaching hospitals). AM was provided in $>120$ outpatient centers (physician and at least 1 anthroposophic therapist) in $14 \mathrm{EU}$ member states, Norway, and Switzerland. Anthroposophic therapies were provided by $>7,000$ anthroposophic therapists ('classical anthroposophic therapies') and nurses in $25 \mathrm{EU}$ member states, in Norway, and in Switzerland. AM was provided in $>500$ institutes for people with learning difficulties in $19 \mathrm{EU}$ member states, Norway, and Switzerland. AM was regularly taught at universities and medical schools in 7 EU member states and Switzerland (university chairs in Germany and Switzerland). AM full training with certificate was provided for medical doctors in $7 \mathrm{EU}$ member states and Switzerland [8]. AM therapy involves specific anthroposophic medicinal products (AMPs) and non-pharmaceutical therapies.

It seems clear that IM may have a lot to offer to the promotion of self-management of (chronic) patients. Therefore, this article explores the contribution of AM, as an IM modality, to the promotion of self-management of patients.

\section{Material and Methods}

Operationalization of Self-Management Promotion

Promotion of self-management of patients was operationalized according to the self-management literature as:

1) Promotion takes place by means of a patient-centered, collaborative approach.

2) Promotion refers to the promotion of being able

a) to cope with symptoms, treatment, physical and social consequences of the chronic disorder, and the associated adjustments in life style;

b) to self-monitor one's own health status and, subsequently, to respond emotionally and behaviorally to one's self-monitoring results in a way that contributes to a satisfying quality of life.

\section{Research Questions}

The research questions that are answered in this study are:

1) Which aspects of the AM worldview, values, concepts, and methods contribute to the promotion of self-management of patients? Which aspects contribute

a) to a patient-centered, collaborative approach of self-management promotion?

b) to patients coping with symptoms, treatment, physical and social consequences of their (chronic) disorder, and the associated adjustments in lifestyle?

c) to patients self-monitoring their own health status and, subsequently, their emotionally and behaviorally responding to the self-monitoring results in a way that contributes to a satisfying quality of life?

2) What are the experiences of patients with the AM self-management promotion approach?

\section{Methods}

The scientific literature on concepts and evidence on AM as well as on patients' experiences with AM and self-management was explored. In addition, 10 semi-structured interviews with patients were audio-analyzed with regard to the experiences with AM in relation to self-management. Relevant data was coded and transcribed, and quotes were categorized thematically. Respondents were selected from the Dutch organization of anthroposophic patients. Illnesses of the respondents varied between minor illnesses (e.g., low hemoglobin levels, common cold), allergies, chronic and progressive diseases, aging problems, psychosomatic conditions, and life-threatening diseases (e.g., cancer and heart failure). Data from the interviews has been published earlier as part of a larger study on patient-relevant outcomes on AM and quality of life [9]. Domains from this analysis that are related to self-management were included in the current literature analysis of AM and self-management. 


\section{Results}

\section{Worldview of AM: A Summary}

Worldviews are frameworks of meaning and meaning-making, shaping how individuals perceive particular issues and their possible solutions. They also tend to influence the willingness of individuals to participate in these worldview-related solutions. Worldviews have 5 interrelated and interdependent aspects: (1) ontology: a perspective on the nature of reality; (2) epistemology: a perspective on how knowledge of reality can come about; (3) axiology: a perspective on what is a good life, in terms of morals and quality of life, ethical and aesthetic values; (4) anthropology: a perspective on what creature the human being is and on his role and position in the universe; and (5) societal vision: a perspective on how society should be organized and how societal problems should be addressed [10].

The worldview of AM is that a human being is, in essence, a spiritual (non-material) being, which, in addition to its spirit, has a soul and a (living) physical body (ontology). The human being is an entity that integrates and balances these different 'levels' that are constantly interacting with each other and the outside world. Health and disease are expressions and results of adequate or inadequate interactions, respectively, between these separate organizational levels of the human being. Treatment is oriented at influencing different aspects of the involved organizing system levels in health and disease at the same time or in phases. One main route of treatment is aiming at restoring balance and wholeness within the system by stimulating the higher levels of organization in order to regulate the lower levels $[6,7,11]$. Anthroposophic treatments of diseases stimulate the self-healing or self-regulation activity of the (organism of the) patient towards an optimal functioning of the higher levels of organization in relation to each other and in their regulation of the lower levels. This means that AM treatments promote a person's physiological and/or psychosocial (self-organizing) ability to adaptively acquire or maintain health across changing personal and environmental conditions $[12,13]$. Therefore, in essence, it is a sustainable health promotion strategy, one that supports and enables patients to actively contribute to and self-manage their own health and disease status [14]. Because AM results from the integration and application of knowledge and methods from conventional medicine and science with anthroposophy, it also integrates and applies the best of both worlds from a 'fighting disease' approach and a health promotion approach [13] (epistemology). According to the spiritual scientific (anthroposophic) position, the human being is developing itself through several lives on Earth (karma and reincarnation) towards optimal self-management, in close relationship with and responsible for the development of all other humans and the Earth [15] (anthropology and societal vision). From these 4 aspects of the AM worldview, 3 important values can be deduced that 'drive' AM healthcare professionals in their interactions with patients: equivalence (between all human beings), servitude (towards the development of other individuals), and presence of mind (in order to be able to find situational solutions) [15] (axiology).
Contributions to a Patient-Centered, Collaborative Approach of Self-Management Promotion

Patient-centered care is a 'holistic (bio-psychosocial-spiritual) approach to delivering care that is respectful and individualized, allowing negotiation of care, and offering choice through a therapeutic relationship where persons are empowered to be involved in health decisions at whatever level is desired by that individual who is receiving the care' ([16], p 3).

AM provides specific contributions to a patient-centered, collaborative approach of self-management promotion. Firstly, the 3 described values that drive AM healthcare professionals (equivalence, servitude, and presence of mind) support a respectful and individualized approach, and allow negotiation of care (shared decisionmaking). Secondly, in AM specific practice methods are used to assess (a) the qualities of the higher organization levels in their relationship to the lower physical and physiological levels [17] and (b) the specific individual and complex situation of the patient. These methods are characterized by exact and non-judgmental observation, a methodological use of empathy and system thinking [18-26].

Empirical patient evaluation studies of AM confirm these contributions from AM to a patient-centered, collaborative approach of self-management promotion. Table 1 shows corresponding items of 3 patient evaluation studies of AM treatments, based on a large qualitative study on patient-relevant contributions of AM to health and quality of life [9]. This qualitative study demonstrates relevant domains regarding a patient-centered collaborative approach, namely 'Care relation' and 'Being well-informed'. Examples from 2 other studies, by Koster et al. [27] and Esch et al. [28], are placed correspondingly. Koster et al. [27] have studied patient experiences with AM general practitioners (GPs), with 2,063 patients from 22 GP practices. Esch et al. [28] report on an observational study that compares patient satisfaction aspects between conventional and AM primary care physicians in Switzerland. In addition to the information in table 1, Koster et al. [27] demonstrated high overall satisfaction with Dutch anthroposophic GP practices: a mean of 8.4 on a scale from 0 to 10 . Esch et al. [28] demonstrated that significantly more AM patients expressed a general treatment satisfaction ( $56.1 \%$ vs. $43.4 \%$ ), saw their expectations completely fulfilled at follow-up (38.7\% vs. $32.6 \%)$ and gave significantly better ratings for thoroughness (70.4\% vs. $56.5 \%)$.

The interviews with patients about their experiences with AM [9] illustrate the described topics: CJ: 'I have an anthroposophic GP and we interact on an equal footing. So communication is very easy.' PN: 'That a doctor can listen with an open mind without assuming things. And ask: what would help you in your situation?' KS: 'Together with others I organize information evenings at the healthcare center. It is much stimulated and facilitated by the care providers. There, I'm a patient, but also a sort of colleague; there is not so much of a gap between me and the GPs or therapists. We do it together, and that is very helpful.'

\section{Contributions to a Better Coping of Patients}

Coping strategies include problem-focused coping and emotion-focused coping strategies. 'Problem-focused coping is directed 
Table 1. Patientcentered collaborative approach: corresponding domains and items from 3 patient evaluation studies

\begin{tabular}{|c|c|c|c|c|c|}
\hline \multicolumn{2}{|c|}{ Koster et al. 2016 [9] } & \multicolumn{2}{|l|}{ Koster et al. 2014 [27] } & \multicolumn{2}{|l|}{ Esch et al. 2008 [28] } \\
\hline Domain level & Item level & $\begin{array}{l}\text { Item level } \\
\text { 'Physician' (Ph.) }\end{array}$ & $\begin{array}{l}\text { Combined \% of } \\
\text { answer categories } \\
\text { 'Most of the time' } \\
\text { and 'Always' }\end{array}$ & $\begin{array}{l}\text { Item level } \\
\text { 'Physician' (Ph.) }\end{array}$ & $\begin{array}{l}\% \mathrm{AM} / \\
\% \text { conventional } \\
\text { medicine }\end{array}$ \\
\hline \multirow[t]{7}{*}{$\begin{array}{l}\text { Care } \\
\quad \text { relation }\end{array}$} & $\begin{array}{l}\text { Trust and } \\
\text { confidence }\end{array}$ & & & $\begin{array}{l}\text { Ph. made it easy to } \\
\text { tell physician about } \\
\text { patient's problem }\end{array}$ & $71.6 / 62.9$ \\
\hline & Communication & $\begin{array}{l}\text { Ph. practiced shared } \\
\text { decision-making }\end{array}$ & 93.9 & $\begin{array}{l}\text { Ph. involved patient } \\
\text { more in decision-making }\end{array}$ & $67.8 / 58.4$ \\
\hline & Human approach & $\begin{array}{l}\mathrm{Ph} \text {. treated patient } \\
\text { with respect }\end{array}$ & 99.4 & $\begin{array}{l}\mathrm{Ph} \text {. had more interest } \\
\text { in personal situation }\end{array}$ & $74.6 / 60.3$ \\
\hline & Being at ease & $\begin{array}{l}\text { Ph. had sufficient } \\
\text { time }\end{array}$ & 96.5 & Ph. spent more time & $76.5 / 61.7$ \\
\hline & $\begin{array}{l}\text { Being heard/seen } \\
\text { Being understood }\end{array}$ & $\mathrm{Ph}$. listened carefully & 98.4 & $\mathrm{Ph}$. listened to patient & $80.0 / 67.1$ \\
\hline & $\begin{array}{l}\text { Being taken } \\
\text { seriously }\end{array}$ & $\begin{array}{l}\mathrm{Ph} \text {. took patient } \\
\text { situation seriously }\end{array}$ & 97.7 & & \\
\hline & Feeling supported & $\begin{array}{l}\mathrm{Ph} \text {. supported self- } \\
\text { management }\end{array}$ & 86.0 & $\begin{array}{l}\text { Ph. helped in dealing } \\
\text { with emotional problems } \\
\text { related to your health } \\
\text { status }\end{array}$ & $61.3 / 49.7$ \\
\hline \multirow[t]{2}{*}{$\begin{array}{l}\text { Being } \\
\text { well- } \\
\text { informed }\end{array}$} & Good information & $\begin{array}{l}\text { Ph. informed patient } \\
\text { about several } \\
\text { treatment options }\end{array}$ & 89.8 & $\begin{array}{l}\text { Ph. explained the } \\
\text { purpose of tests and } \\
\text { treatments }\end{array}$ & $68.0 / 60.2$ \\
\hline & & $\begin{array}{l}\text { Ph. explained test } \\
\text { results } \\
\text { understandably }\end{array}$ & 95.5 & $\begin{array}{l}\text { Ph. told what patient } \\
\text { wanted to know about } \\
\text { symptoms and/or illness }\end{array}$ & $69.9 / 60.2$ \\
\hline
\end{tabular}

at the stressor itself: taking steps to remove or to evade it, or to diminish its impact if it cannot be evaded.' ... 'Emotion-focused coping is aimed at minimizing distress triggered by stressors. Because there are many ways to reduce distress, emotion-focused coping includes a wide range of responses, ranging from self-soothing (e.g., relaxation, seeking emotional support), to expression of negative emotion (e.g., yelling, crying), to a focus on negative thoughts (e.g., rumination), to attempts to escape stressful situations (e.g., avoidance, denial, wishful thinking)' ([29], p 685).

AM contributes to patients developing better coping strategies. Firstly, it provides a spiritual worldview that serves as a coping strategy. Secondly, coping is improved by treating patients in such a way that they (further) develop self-regulating functioning both on the physiological and the psychosocial level, thus enabling their self-management of disease-related symptoms. Finally, AM treatments (non-verbally) improve emotion-focused coping skills.

Current knowledge in the research field of spirituality/religiosity demonstrates that the utilization of spirituality can be regarded as an active coping process [30]. Firstly, spirituality is strongly associated with better health behavior habits (e.g., lower smoking and alcohol consumption), is more strongly linked to biomarkers and is positively related to a variety of indicators of mental health, including subjective well-being and personality dimensions [31]. Secondly, spirituality can play an important role in recovering from mental illness and protection against addictive or suicidal behaviors [32]. Finally, a spiritual worldview can result in a cognitive change. This means that the spiritual concepts may change the way we appraise the situation we are in, to alter its emotional significance, either by changing how we think about the situation or by changing our capacity to manage the demands it poses [33].

The symptom and stress-reducing effects of AM therapies have been demonstrated in several studies, e.g., overall [34], in non-verbal treatment with, for example, eurythmy therapy [35, 36], art therapy [37, 38], rhythmical massage [39, 40], with medicinal products (e.g., [41-46]), and in complex AM treatment for chronic indications $[47,48]$.

Empirical patient evaluation studies also confirm the contribution of AM regarding developing better coping strategies of patients. Relevant domains from Koster et al. [9] are 'Natural healing', 'Active contribution/Autonomy' and 'Meaning'. Table 2 shows corresponding items of Koster et al. [27] and Esch et al. [28] within these domains. In addition to the information in table 2, Koster et al. [27] demonstrated that patients experienced positive effects of AM treatment on symptoms (89.8\%) and quality of life (76\%), and Esch et al. [28] demonstrated that AM patients reported significantly fewer adverse side effects (9.3\% vs. $15.4 \%)$ and more other positive treatment effects ( $31.7 \%$ vs. $17.1 \%)$.

The interviews with patients about their experiences with AM [9] illustrate the described topics: GH: 'I went to an anthroposophic doctor, because with my conventional GP I could not speak about other aspects of my disease and the story of my biography.' And: 'I'd like to be more positive and deal better with my feelings 
Table 2. Coping: corresponding domains and items from 3 patient evaluation studies

\begin{tabular}{|c|c|c|c|c|c|}
\hline \multicolumn{2}{|c|}{ Koster et al. 2016 [9] } & \multicolumn{2}{|l|}{ Koster et al. 2014 [27] } & \multicolumn{2}{|c|}{ Esch et al. 2008 [28] } \\
\hline Domain level & Item level & $\begin{array}{l}\text { Item level 'Physician' (Ph.) } \\
\text { or 'Treatment' (Tr.) } \\
\text { or 'Worldview' (Wv.) }\end{array}$ & $\begin{array}{l}\text { Combined \% of } \\
\text { answer categories } \\
\text { 'Most of the time' } \\
\text { and 'Always' }\end{array}$ & $\begin{array}{l}\text { Item level } \\
\text { Physician } \\
(\mathrm{Ph} .)\end{array}$ & $\begin{array}{l}\% \mathrm{AM} / \\
\% \text { conventional } \\
\text { medicine }\end{array}$ \\
\hline \multirow[t]{2}{*}{$\begin{array}{l}\text { Natural } \\
\text { healing }\end{array}$} & $\begin{array}{l}\text { No/less adverse } \\
\text { effect }\end{array}$ & Prevalence of side effects & 6.0 & $\begin{array}{l}\text { Fewer } \\
\text { adverse or } \\
\text { side effects }\end{array}$ & $9.3 / 15.4$ \\
\hline & $\begin{array}{l}\text { Support and use of } \\
\text { physiological self- } \\
\text { regulation }\end{array}$ & $\begin{array}{l}\text { Ph./Tr. supported physiological } \\
\text { self-regulation }\end{array}$ & 84.2 & & \\
\hline \multirow{3}{*}{$\begin{array}{l}\text { Active } \\
\text { contribution/ } \\
\text { Autonomy }\end{array}$} & $\begin{array}{l}\text { Keystone form } \\
\text { coping }\end{array}$ & $\begin{array}{l}\text { Ph./Tr. motivated to contribute } \\
\text { actively to one's own health }\end{array}$ & 84.1 & & \\
\hline & Self-responsibility & $\begin{array}{l}\text { Ph. assessed one's self-respon- } \\
\text { sibility for choices regarding } \\
\text { one's health }\end{array}$ & 73.4 & & \\
\hline & Grip/self-control & $\begin{array}{l}\text { Ph. practiced shared decision- } \\
\text { making }\end{array}$ & 93.9 & & \\
\hline \multirow[t]{4}{*}{ Meaning } & $\begin{array}{l}\text { Insight regarding } \\
\text { health and disease }\end{array}$ & $\begin{array}{l}\text { Wv. enabled to better under- } \\
\text { stand one's health problem }\end{array}$ & 80.2 & & \\
\hline & $\begin{array}{l}\text { Meaning within the } \\
\text { big picture }\end{array}$ & $\begin{array}{l}\text { Wv. enabled to give meaning } \\
\text { to health problem in relation to } \\
\text { one's personal life }\end{array}$ & 80.8 & & \\
\hline & $\begin{array}{l}\text { Personal } \\
\text { development }\end{array}$ & $\begin{array}{l}\text { Ph./Tr./Wv. supported personal } \\
\text { development }\end{array}$ & 77.6 & & \\
\hline & Holistic vision & $\begin{array}{l}\text { Wv. enabled to give spiritual } \\
\text { meaning to health problem }\end{array}$ & 50.9 & & \\
\hline
\end{tabular}

of suffering. (...) Biographic counselling gives me self-acceptation and help to step out of the pattern of feeling a victim of things. (...) And anthroposophy gives me tools to look to suffering from a different perspective.' MJ: 'Rhythmic massages made me feel stronger and reduced my stress symptoms.' SM: 'My physiological self-regulation has been completely wiped out during the last year, but it just revives, so it's still there! I try to have confidence and support my physiological self-regulation, especially with mistletoe therapy. For me it works very stimulating.' JC: 'In conventional care I miss the extras of anthroposophy, for example, its medication. Effects of anthroposophic medication are that you are slowly really getting better. You feel fitter and you get more energy.' SM: 'To have different possibilities to choose, no matter how small, helped me to feel less overwhelmed by everything, (...) by making the little steps I had chosen myself I could get used to changing situations easier and that made me cope with and accept the current situation better.' SK: 'To treat migraine I've had rhythmic massages. (...) I think the migraine was caused by stress and my chaotic way of being. To give me this thorough relaxation I came to myself again and could make priorities, knowing again what is important to me, my family, my child, and sometimes just doing nothing at all.'

\section{Contributions to Self-Monitoring of the Patients' Own Health Status}

Self-monitoring refers to the ability to notice our own actions, the curiosity to examine the effects of those actions, and the will- ingness to use those observations to improve future behavior and thinking [49].

Self-monitoring in conventional medicine often implies monitoring of self-measurements with medical instruments (e.g., blood pressure, blood glucose). In AM, self-monitoring implies the monitoring (self-reflection) of (1) the quality of one's own activity during treatment (e.g., monitoring the quality of a movement one performs in eurhythmy therapy), (2) how one deals with treatmentand health-related issues (e.g., self-research in one's biography), and of (3) the physiological and/or psychological responses to these self-reflection activities. This type of self-monitoring is supported by mindfulness-like training of non-judgmental attention skills (by means of, e.g., Goetheanistic methods and/or meditation training) and the application of AM concepts (of health and disease, healing processes, and the relationship between disease and AM treatment), resulting in a cognitive change of how one thinks about the situation or of one's capacity to manage the demands it poses. The development of this type of self-monitoring often results in the situation that patients develop a better connection with (the signals of) their body and mind, a better judgement regarding their health issues, and more responsibility towards and confidence in steering their own health situation. In addition, a meaningful and personal connection between one's life and illness, which empowers a patient as a human being in general, can develop or can be strengthened.

Supportive evidence comes from mindfulness(-related) research. For example, Hölzel et al. [50] demonstrate that mindful- 
ness training results in a decrease in distress as well as an increase in positive mood states by means of effects on attention regulation, body awareness, and emotion regulation, and a change in self-perspective. Büssing et al. [51] demonstrated that active (emotional) engagement of individuals practicing these types of therapy is associated with stress and symptom reduction and increases of life satisfaction and quality of life.

Self-monitoring is also confirmed from the patients' perspectives in Koster et al. [9]. Monitoring is one of the items within the domain of 'Being well informed'. Reflective self-monitoring is confirmed by means of the domain 'Mindful inner attitude'. Relevant items are 'Self-awareness', 'Emotional reactions on treatment', 'Body awareness', 'Acceptance', and 'Confidence in own body'.

The interviews with patients about their experiences with AM [9] illustrate the described topics: MD: 'Physiological self-regulation is the starting point, a force from the person itself $(\ldots)$ that wants to stay alive. (...) Being aware of what you feel and what you need, and act towards it. (...) You have to listen to it.' GH: ' $\ldots$ because I have to take care that my physiological self-regulation can function properly, and I think that it only does when I listen to the signals my body gives me.' JC: 'When I get ill, first I evaluate what I have done the last few weeks or months. Did I take more than I can handle? I try to accept it and adjust my lifestyle, so that after a while I'll find a balance again.' ER: 'Therapy gives me support and advice so I can do it myself, and to practice what I have learned. (...) I have a stone in my pocket. A trick to stay in the here and now. It is the force I need to fulfil something.'

\section{Conclusions}

AM offers specific contributions to the promotion of the selfmanagement of patients.

1) Contributions of $\mathrm{AM}$ to the patient-centered, collaborative promotion of the self-management of patients are:

a) the application of basic values (equivalence, servitude, and presence of mind) by healthcare professionals, and

b) the application of specific methods by healthcare professionals to assess the qualities of the higher organization levels in their relationship to the lower physical and physiological levels of the human being and the specific individual and complex situation of the patient.

2) Contributions of AM to the improvement of the coping strategies of patients with health-related issues are:

a) the provision of a spiritual worldview that serves as a coping strategy;

b) treatment of patients in such a way that they (further) develop self-regulating functioning, both on the physiological and the psychosocial level, thus enabling the self-management of disease-related symptoms, and

c) treatment of patients with (non-verbal) therapies in order to improve their emotion-focused coping skills.
3) The contribution of AM to an improvement of the self-monitoring of the patients' own health status comprises:

a) training of the patients' monitoring skills of reflecting on one's own activity during treatment, of how one deals with treatment- and health-related issues, and on the physiological and/or psychological reactions to these self-reflection activities.

4) The specific contributions of AM to the promotion of selfmanagement of patients derived from the AM worldview, concepts, and methods have been confirmed by qualitative and quantitative patient evaluation research.

\section{Discussion}

One major current development in healthcare is that the individual patient with his/her personal environment is moving more and more into the center of attention and is increasingly perceived as an equal partner alongside the healthcare professionals. Expressions of this development are the increase of shared decision-making and the increasing emphasis on self-management of patients. In this article, we explored the specific contributions of AM to selfmanagement of patients. We demonstrated that, within the current definition of self-management, AM has specific contributions that are experienced by patients as demonstrated in patient evaluation studies.

A limitation of this article is its scoping character, exploring the relevant topics and supporting the described conceptual domains with evidence from clinical research and qualitative and quantitative studies on patient experiences, although not systematically collected. Future studies should therefore focus on a more systematic review of the literature and more empirical studies in this field. However, given the increasing emphasis on patient self-management in healthcare which is completely in line with the AM values and worldview, supporting optimal self-management of patients could and should be further developed as an important branch of AM.

\section{Disclosure Statement}

E.W.B. and E.B.K. are working at the Professorship Anthroposophic Healthcare at the University of Applied Sciences Leiden, The Netherlands. The professorship is partly funded by organizations in the field of AM in The Netherlands. However, the authors were not influenced by any person or organization in writing or submitting this article. 


\section{References}

1 Wagner EH, et al: Quality improvement in chronic illness care: a collaborative approach. Jt Comm J Qual Patient Saf 2001;27:63-80.

2 Goldstein MS: The persistence and resurgence of medical pluralism. J Health Polit Policy Law 2004;29:925945.

3 Coleman MT, Newton KS: Supporting self-management in patients with chronic illness. Am Fam Physician 2005; 72:1503-1510.

4 Academic Consortium for Integrative Medicine \& Health, https://www.imconsortium.org/, 2016.

5 World Health Organization: WHO traditional medicine strategy 2014-2023. Geneva, World Health Organization, 2015.

6 Kienle G, et al: Anthroposophic medicine: an integrative medical system originating in Europe. Glob Adv Health Med 2013;2:20-31.

7 Steiner R, Wegman I: Grundlegendes für eine Erweiterung der Heilkunst nach geisteswissenschaftlichen $\mathrm{Er}$ kenntnissen. Dornach, Rudolf Steiner Verlag, 2000.

8 International Federation of Anthroposophic Medical Associations (IVAA): The system of Anthroposophic Medicine. Brussels, IVAA, 2012.

9 Koster EB, Baars EW, Delnoij DM: Patient-centered outcomes on quality of life and anthroposophic healthcare: a qualitative triangulation study. Qual Life Res 2016;1-11.

10 Hedlund-de Witt A: Exploring worldviews and their relationships to sustainable lifestyles: towards a new conceptual and methodological approach. Ecol Econ 2012;84:74-83

11 Heusser P: Anthroposophische Medizin und Wissenschaft: Beiträge zu einer integrativen medizinischen Anthropologie. Stuttgart, Schattauer Verlag, 2011.

12 Boekaerts M, Pintrich PR, Zeidner M: Handbook of Self-Regulation. Amsterdam, Elsevier, 2005

13 Baars E: Evidence-based curative health promotion: a systems biology-orientated treatment of seasonal allergic rhinitis with Citrus/Cydonia comp. PhD Thesis, Wageningen Universiteit, Wageningen, 2011.

14 Baars E: Evidence-based curative health promotion. Wageningen, Wageningen University, 2011.

15 Baars E: Goede zorg - Ethische en methodische aspecten. Zeist, Christofoor, 2005

16 Morgan S, Yoder LH: A concept analysis of personcentered care. J Holist Nurs 2012;30:6-15.

17 Van der Bie G, Huber M: Foundations of Anthroposophical Medicine: A Training Manual. Edinburgh, Floris Books, 2003.

18 Baars E, van der Meij A: Imaginatie, Inspiratie, Intuïtie. Handboek onderzoeksmethoden. Amsterdam, Uitgeverij SWP, 2011.

19 Bortoft H: The Wholeness of Nature. Goethe's Way of Science. New York, Lindisfarne Press, 2010

20 Kruse D: Seelisches Beobachten in der Natur. Kirchlinteln, Menschenbildverlag, 2003.
21 Schmidt D: Lebenskräfte - Bildekräfte, Methodische Grundlagen zur Erforschung des Lebendigen. Stuttgart, Verlag Freies Geistesleben, 2010.

22 Sijmons J: Phänomenologie und Idealismus: Struktur und Methode der Philosophie Rudolf Steiners. Basel, Schwabe, 2008

23 Steiner R: Die Geheimwissenschaft im Umriss. Dornach, Rudolf Steiner Verlag, 2012.

24 Steiner R: Wie erlangt man Erkenntnisse der höheren Welten? Hamburg, Severus Verlag, 2014.

25 Ziegler R: Intuition und Ich-Erfahrung: Erkenntnis und Freiheit zwischen Gegenwart und Ewigkeit. Edition Hardenberg. Stuttgart, Verlag Freies Geistesleben, 2006.

26 Uitgeest W: Bang voor rood, geel en.... blauw?: Goethe, Merleau-Ponty en fenomenologisch kleuronderzoek. PhD. Amsterdam, Free University, 2016.

27 Koster EB, et al: The consumer quality index anthroposophic healthcare: a construction and validation study. BMC Health Serv Res 2014;14:1.

28 Esch BM, et al: Patient satisfaction with primary care: an observational study comparing anthroposophic and conventional care. Health Qual Life Outcomes 2008;6:1.

29 Carver CS, Connor-Smith J: Personality and coping. Annu Rev Psychol 2010;61:679-704.

30 Büssing A, Ostermann T, Koenig HG: Relevance of religion and spirituality in German patients with chronic diseases. Int J Psychiatry Med 2007;37:39-57.

31 Aldwin CM, et al: Differing pathways between religiousness, spirituality, and health: a self-regulation perspective. Psycholog Relig Spiritual 2014;6:9.

32 Unterrainer H-F, Lewis A, Fink A: Religious/spiritual well-being, personality and mental health: a review of results and conceptual issues. J Relig Health 2014;53: 382-392.

33 Webb TL, Miles E, Sheeran P: Dealing with feeling: a meta-analysis of the effectiveness of strategies derived from the process model of emotion regulation. Psychol Bull 2012;138:775

34 Kienle GS, et al: Clinical research on anthroposophic medicine: update of a health technology assessment report and status quo (in German). Forsch Komplementmed 2011;18:269-282.

35 Kanitz JL, et al: The impact of eurythmy therapy on stress coping strategies and health-related quality of life in healthy, moderately stressed adults. Complement Ther Med 2011;19:247-255.

36 Büssing A, et al: Eurythmy therapy in clinical studies: a systematic literature review. BMC Complement Altern Med 2008;8:1.

37 Bar-Sela G, et al: Art therapy improved depression and influenced fatigue levels in cancer patients on chemotherapy. Psychooncology 2007;16:980-984.

38 Hamre HJ, et al: Anthroposophic art therapy in chronic disease: a four-year prospective cohort study. Explore (NY) 2007;3:365-371.
39 Wälchli C, et al: Physiologic effects of rhythmical massage: a prospective exploratory cohort study. J Altern Complement Med 2014;20:507-515.

40 Hamre HJ, et al: Rhythmical massage therapy in chronic disease: a 4-year prospective cohort study. J Altern Complement Med 2007;13:635-642.

41 Baars E, et al: A comparative in vitro study of the effects of separate and combined products of Citrus e fructibus and Cydonia e fructibus on immunological parameters of seasonal allergic rhinitis. Mediators Inflamm 2012;2012:109829.

42 Baars E, Savelkoul H: Citrus/Cydonia comp. can restore the immunological balance in seasonal allergic rhinitis-related immunological parameters in vitro. Mediators Inflamm 2008;2008:496467.

43 Baars EW, Bruin AD: The effect of Gencydo ${ }^{\circledR}$ injections on hayfever symptoms: a therapeutic causality report. J Altern Complement Med 2005;11:863-869.

44 Baars EW, et al: Citrus/Cydonia compositum subcutaneous injections versus nasal spray for seasonal allergic rhinitis: a randomized controlled trial on efficacy and safety. ISRN Allergy 2011;2011:836051.

45 Baars EW, Nierop AF, Savelkoul HF: Development of systems biology-oriented biomarkers by permuted stepwise regression for the monitoring of seasonal allergic rhinitis treatment effects. J Immunol Methods 2012;378:62-71.

46 Hoffmann A, et al: Efficacy of a nasal spray from Citrus limon and Cydonia oblonga for the treatment of hay fever symptoms - a randomized, placebo controlled cross-over study. Phytother Res 2016;30:1481-1486.

47 Hamre HJ, et al: Long-term outcomes of anthroposophic treatment for chronic disease: a four-year follow-up analysis of 1510 patients from a prospective observational study in routine outpatient settings. BMC Res Notes 2013;6:1.

48 Ketelaars D, Baars E, Kroon H: Healing through Working. A Study of Therapeutic Communities for Persons with Psychiatric Problems. New York, Mercury Press, 2001.

49 Epstein RM, Siegel DJ, Silberman J: Self-monitoring in clinical practice: a challenge for medical educators. J Contin Educ Health Prof 2008;28:5-13.

50 Hölzel BK, et al: How does mindfulness meditation work? Proposing mechanisms of action from a conceptual and neural perspective. Perspect Psychol Sci 2011; 6:537-559.

51 Büssing A, et al: Inner correspondence and peacefulness with practices among participants in eurythmy therapy and yoga: a validation study. Evid Based Complement Alternat Med 2011;2011:329023. 